\title{
A Common Sense-Based On-Line Assistant for Training Employees
}

\author{
Junia Coutinho Anacleto ${ }^{1}$, Muriel de Souza Godoi ${ }^{1}$, \\ Aparecido Fabiano Pinatti de Carvalho ${ }^{1}$, and Henry Lieberman ${ }^{2}$ \\ ${ }^{1}$ Advanced Interaction Laboratory - LIA \\ UFSCar - Rod. Washigton Luis KM 235 - São Carlos - SP - Brazil \\ \{junia, alessandro_carlos, muriel_godoi, \\ fabiano, vania\} @dc.ufscar.br \\ ${ }^{2}$ MIT Media Laboratory \\ 20 Ames St., 384A - Cambridge - MA - 02139 \\ lieber@media.mit.edu
}

\begin{abstract}
We present a prototype of an on-line assistant to support a training course about workspace safety issues. The application uses a common sense reasoning engine and the Brazilian Open Mind common sense knowledge base, to make inferences about concepts that might be unfamiliar to the students. We explore the use of metaphors and analogies to explain topics, enhancing learning by using similarities to help students associate related topics. We believe that common sense can be used to take into account cultural considerations while helping learners to build analogies. A survey of students showed that they considered analogies useful in the learning process, that the system was helpful in understanding new concepts, and that it helped connect the information searched for with common sense knowledge.
\end{abstract}

Keywords: Distance learning, common sense, on-line assistant, training, education, cognitive strategies, metaphors and analogies.

\section{Introduction}

This article discusses the automatic use of common sense knowledge to support a Distance Learning (DL) course in a company with more than five hundred thousand employees that must be continually trained about workspace safety issues in order to prevent accidents.

We are developing an on-line assistant application that uses a common sense reasoning engine and the common sense knowledge base of the Brazilian Open Mind Common Sense (OMCS-Br) Project [5], to make inferences about concepts that employees are looking for.

We define "common sense" as the knowledge that most people agree with in a certain community at a certain period of time $[1,2]$.

Considering time and space constraints that people face in their daily work life, computer-based DL can be a solution to meet the current demand for continuing education [25] Nevertheless, the physical distance between teachers (here, the 
company's trainers) and students (the company's employees), distance learning reduces the opportunities for teachers to know about particular students' difficulties and to intervene in the learning process [8] in time to correct misconceptions or supply missing knowledge. In particular, the clarity of the material presented by the computer is crucial, since it has to be capable of helping students clarify any questions or doubts that appear during their studies [8].

Another way of enhancing DL is to use common sense knowledge to plan learning actions. Common sense is being used in the learning process in order to achieve pedagogical goals $[3,4,9]$.

It is often possible to find metaphors and analogies in common sense knowledge bases [15] and, according to Liebman [16] and Neris et al. [18,19], these elements can be used as a stimulus to activate the use of cognitive strategies by the learner.

Cognitive strategies are defined by Gagné as skills, internally organized, which learners use to guide their processes of attention, learning, memory and thinking. The elements used to stimulate such strategies are called cognitive operators [14].

Our on-line assistant looks for metaphors and analogies in common sense knowledge base, and uses those elements as important components of the explanation process. It presents the concepts sought by the user in the context retrieved, along with common sense analogies, which help to understand the information presented.

This paper is organized as follows: the next section presents a discussion about how analogy supports learning. (Subsequently, we will refer to learning, teachers, and students; this generalizes the specific situation of workplace training, trainers and employees for which our prototype was aimed). The following section explains how common sense analogies can be found in a large common sense knowledge base. In the next section, the on-line assistant is presented. Then, we present some results of a user test with the system, evaluating the data presentation and the relevance of the analogies provided. Finally we present some conclusions, discussing our preliminary results and the potential for future work.

\section{Analogies and the Learning Process}

The use of analogies is one cognitive strategy adopted by people when they want to understand some concept, and a cognitive operator that is used to make other people understand a concept being explained. This is because it is easier to understand new information when relating it to life experiences $[3,17]$.

Ausubel explains this phenomenon when he defines meaningful learning concepts [5]. For Ausubel, in order to have effective learning, the new piece of knowledge which is being taught should be presented to the learner so that it can be related to other pieces of knowledge which are already in their cognitive structure.

As an example, let's suppose that, in the learner's mind, the concept "fire" is related to the concepts of "danger" and "accident". Then the new concept "electric spark" is presented in the learning material. If "electric spark" is close to "fire", then the associated concepts "danger" and "accident" can be used to make an analogy between "fire" and the new concept "electric spark". So it helps the learner to know that, like fire, electrical sparks are dangerous and can cause accidents. 
This approach of using analogies can also be justified by Paulo Freire's theories. For Freire, for learning to be successful, teachers should be concerned with the learner's common sense, to stimulate their creativity [12]. In keeping with Freinet's theory [13], if students are familiar with cities, teacher should use elements like cars, stores, buildings, and so on. If the students are familiar with farms, concepts such as animals and plants would be more suitable to make them understand what is being explained. Furthermore, analogies can also be related to Gagné's Instructional Theory [14]. According to Gagné, learners make use of several strategies to guide their processes of attention, learning, memory and thinking. The use of these cognitive strategies is very important to fix the knowledge in learners' cognitive structure and thus to effective learning.

Although cognitive strategies are skills organized internally by the student, as presented in Gangé's Instructional Theory, Neris et al. [18,19] maintain that teachers can make use of some external elements, the cognitive operators, to stimulate their use. For instance, professors can present some analogies to students so that they can activate the same internal skill (analogies) on their own. The cognitive strategy Association can be directly related to analogies since analogy can be defined as a comparison between things which have similar features as well the strategy Metaphors and analogies. Stamm [21] mentions that activating the cognitive strategy called Analogy in the students can activate the learning surprises that professors frequently desire.

It is interesting to point out how analogies lead to connections among things a person already has in mind, i.e., cognitive structure. Making these connections means to promote meaningful learning, and this is only possible because the information presented can be related to something that the student already knows, i.e., it is contextualized to his or her background knowledge.

\section{Finding Metaphors and Analogies in Open Mind Common Sense Knowledge Base}

This study has been using the OMCS-Br knowledge base to automatically build the analogies presented by the online assistant. This knowledge base has been built using the collaborative approach adopted by the versions of the Open Mind Common Sense (OMCS) Project, which is based on the idea that ordinary people can contribute the common sense knowledge needed to make computers more intelligent [21].

The Brazilian version of the project has been developed since August 2005, and now it has in its knowledge base approximately 137.000 sentences, which were gotten from volunteer contributors on the project website (www.sensocomum.ufscar.br).

Lieberman et al. [15] have already demonstrated the possibility of building common sense analogies from the data stored in OMCS knowledge bases, bridging the mismatch between the specialized knowledge and technical vocabulary of experts who are providing help, and the relative naïveté of novices, who are usually not in a position to understand solutions expressed by the expert in their own terms.

SuggestDesk, the assistant which presents common sense analogies, watches the interaction between the novice and the helper, and suggests to the helper analogies that will help him/her elicit problem information from the user and explain technical 
solutions. Besides SuggestDesk, there was also an e-mail client in the context of the OMCS Project, What is he thinking (WIHT). WIHT watches the user's input during e-mail editing, alerting the user to possibly relevant cultural differences and analogies, regarding the eating habits domain, for concepts that evoke a similar social meaning in those cultures [11]. Another version of WIHT was developed to work on four semantic networks [1]: the OMCSNet (OMCSNet.OM), which was mined from the Open Mind corpus, and three culturally specific knowledge bases - the Brazilian (OMCSNet.BR), the Mexican (OMCSNet.MX) and North-American (OMCSNet.US) semantic networks. The OMCSNet.BR was built from data mined from the Brazilian Open Mind Common Sense database [1,2].

The intelligent agent implemented in WIHT is capable of making analogies between the networks. This is possible by comparing the set of tuples retrieved from a contextual search in the American and Mexican, and the Brazilian and American semantic networks. For instance, the contextual search in the American network would return relations such as:

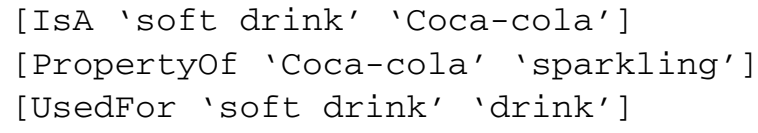

At the same time, the contextual search in the Brazilian network would return relations such as:

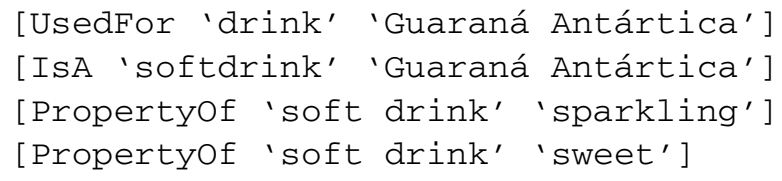

Having those sets of relations, the intelligent agent compares them. If the value of one node and the semantic relations in the tuples of one set are equal to the tuples of the other cultural set, then the differentiating concept is an analogy between the two cultures that are being considered. These processes are similar to Gentner's Structure Mapping analogy method $[11,1,2]$.

\section{On-Line Assistant with Common Sense}

The online assistant uses a similar approach to that used in SuggestDesk and WIHT systems.

In this context, in order to be possible to make the intended analogies, it was necessary to build a domain-specific knowledge base, ExpertNet, using the same knowledge representation used in ConceptNet. This knowledge base was built by a Knowledge Engineer, based on information from several documents about workplace safety issues provided by the company. When the student searches for a concept, it compares the set of relations retrieved from ExpertNet to the set of relations retrieved from ConceptNet so that analogies can be made. The approach used here is similar to WIHT, but applied to a new domain. 
The version of ConceptNet used in this experiment is a semantic network automatically mined from the OMCS-Br corpus, and represented as a set of binary assertions. Considering that the application is intended as a tool for distance learning, it has been designed to run over the web. Therefore, we considered such issues as bandwidth constraints, which directly affect system response time and user satisfaction. Again, because of the application's purpose, we adopted a Web service architecture. This architecture is characterized by making available the searching methods of the ConceptNet's API, implemented in Python, in a ConceptNet server that receives requests from web applications, as depicted in Figure 1. Additionally, we developed a Java module, the OMCS Client, which uses the XMLRPC protocol to connect itself to the server and access the API methods, mapped as Web services. Finally, we developed a website using JSP technology, where students perform their searches.

When students provide a search query, the web server establishes a connection to the ConceptNet server through the OMCS Client module. Then the ConceptNet server lemmatizes the expression which was sent by the OMCS Client and makes inferences about it, considering the morphological variations of the words that compose the expression. Having identified the variations, the ConceptNet's API returns all relations and analogies which contain at least one of those variations.

In order to identify the morphological variations, the system uses two techniques. The first one is the expansion technique. It is useful when students use short expressions to perform the search. In this technique, the terms related to the context are retrieved by ConceptNet's Get-Context method. Then, terms that have the lemmatized expression as a substring are also retrieved. For instance, when a student provides the expression "fire" in the search's area, which is depicted in Figure 2, the system will also search for expressions like "fire alarm", "fire place", "fire door" and so on.

The second technique is useful especially when large expressions are provided by the students to be searched. In this case phrasal structures, such as noun phrases, verbal phrases and adjective phrases are identified by the system and then the system performs a search for each structure identified. For example, when a student asks the

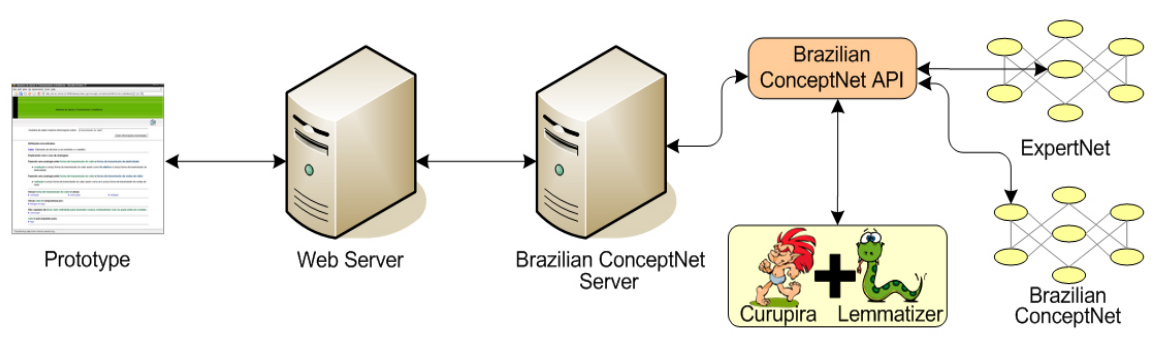

Fig. 1. The help assistant architecture

system for results related to the expression "preventing accidents in the workplace", the expression will be divided in "preventing work accidents", "work accidents", "accidents" and "accident in the workplace". This technique increases the likelihood of getting results from the search, since the terms that are searched are simpler and more likely to be found in the semantic network. 


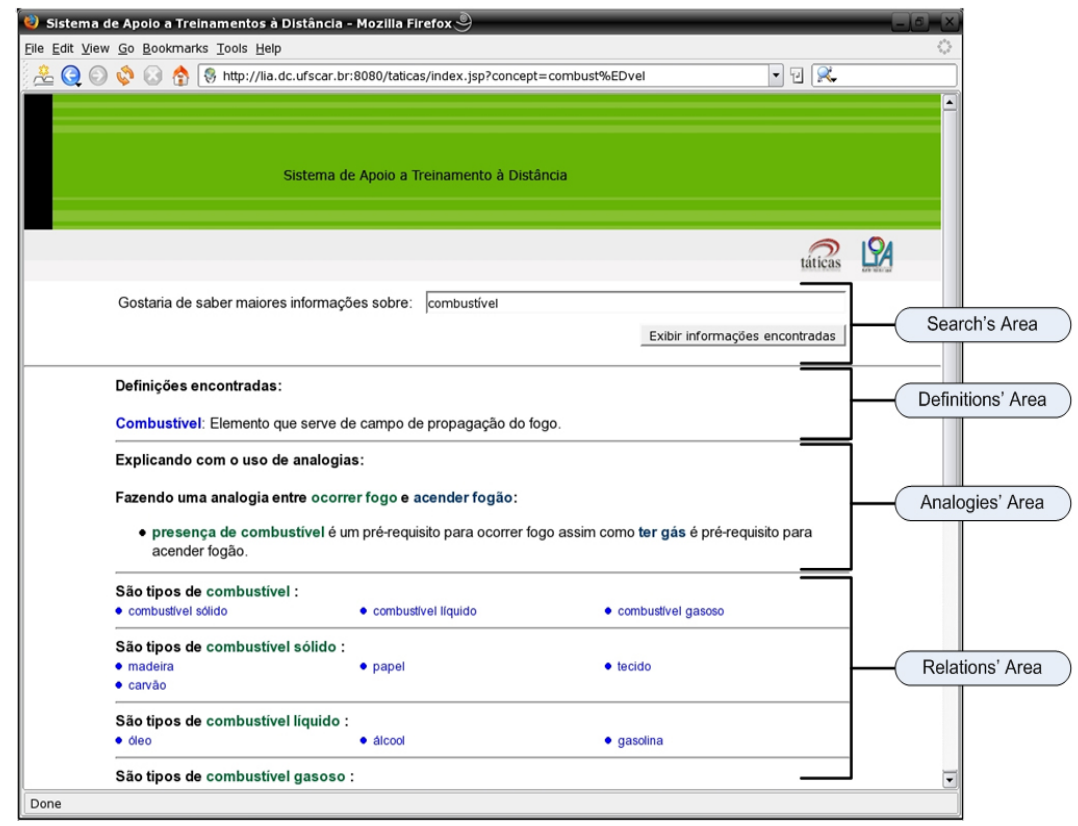

Fig. 2. Screenshot of the online assistant to distance training in work security subject

Once the system identifies the related concepts and analogies, they are presented to the student considering 4 categories in the following order:

\section{Definitions;}

2. Analogies;

3. Relations; and

4. Related Concepts.

The first three categories can be observed in Figure 2. The fourth is presented in Figure 4. It is important to point out that all expressions retrieved from ConceptNet and ExpertNet are presented by the system as links. By clicking on one of those links, a new search is automatically performed in the semantic network, and new results are presented to the user.

In the Definitions' area the system presents the explanation of the concepts, retrieved from the search performed by the student, which were found in ExpertNet. Students can find the information they need about the expressions they are looking for in this area.

The Analogies' area presents analogies computed by the system. Here the common sense analogies help students understand the explanations presented in the Definition area. The analogies are presented as sentences of the form, $X$ relation $Y$, as A relation $B$ where relation is the type of relation that connects those items in the ConceptNet.

An example is presented in Figure 3. We use analogies from the workplace domain to the domain of everyday life. Analogies explain specific topics with generalized examples from commonsense. In this figure, we present an example concerning the factors likely to cause workplace accidents. 


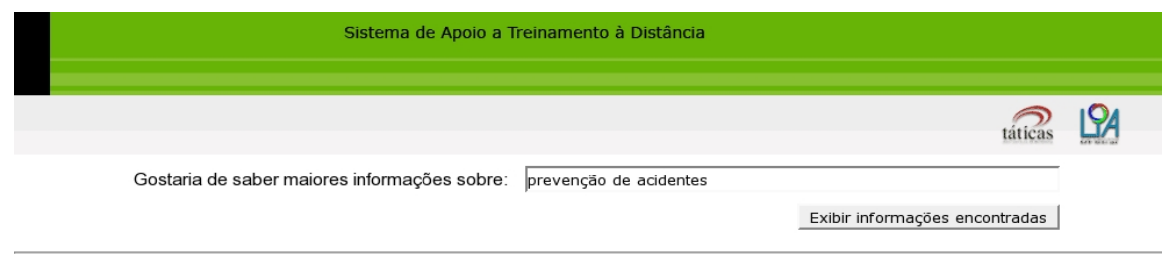

Definições encontradas:

Acidente: Ocorrência imprevista e indesejável que provoca lesão pessoal.

Acidente de trabalho: É o que ocorre pelo exercício do trabalho a serviço da empresa ou ainda pelo exercício do trabalho dos segurados especiais, provocando lesão corporal ou perturbação funcional que cause a morte, a perda ou redução da capacidade para o trabalho, permanente ou temporário. Decreto Lei nº. 2172/97.

Explicando com o uso de analogias:

Fazendo uma analogia entre fator pessoal causador de acidente de trabalho e fator causador de acidente em casa:

- colocar parte do corpo em lugar perigoso é um(a) fator pessoal causador de acidente de trabalho assim como pessoa dependurar na janela é um(a) fator causador de acidente em casa.

- usar maquina sem habilitação ou permissão é um(a) fator pessoal causador de acidente de trabalho assim como criança utilizar fogão é um(a) fator causador de acidente em casa.

- imprimir excesso de velocidade ou sobrecarga é um(a) fator pessoal causador de acidente de trabalho assim como criança correr na cozinha é um(a) fator causador de acidente em casa.

- lubrificar ajustar e limpar máquina em movimento é um(a) fator pessoal causador de acidente de trabalho assim como limpar fogão com chama acesa é um(a) fator causador de acidente em casa.

- inutilizar dispositivos de segurança é um(a) fator pessoal causador de acidente de trabalho assim como rasgar luva para pegar assadeira é um(a) fator causador de acidente em casa.

Fig. 3. An example of using analogy from common sense to explain a concept

These factors are explained by making analogies to factors that cause accidents in the home. For example:

- To expose a part of your body to dangerous machinery is like a person that leans out of a window.

- Using a machine in the workplace without proper permission is like letting a child use the stove in a kitchen.

- Adjusting or Cleaning a Machine while it is moving is like cleaning the stove with the flame on.

In the Relations' area, we show the connection among some terms of ConceptNet, related to the context retrieved. Students can use the links presented in this area to explore new concepts and enhance their learning.

Finally, we present the Related Concepts' area, shown in Figure 4. This area has some contextualized terms that can also be used by students to guide their learning process.

$\begin{array}{ll}\text { Conceitos relacionados: } & \\ \text { - combustivel } & \text { - combustivel sólido } \\ \text { - combustivel gasoso } & \text { - liquido } \\ \text { - eliminação } & \text { - abafamento } \\ \text { - calor } & \text { - proximidades } \\ \text { - elemento } & \text { - madeira } \\ \text { - carvão } & \text { - óleo } \\ \text { - presença } & \text { - outros gases } \\ \text { - serve } & \text { - campo }\end{array}$

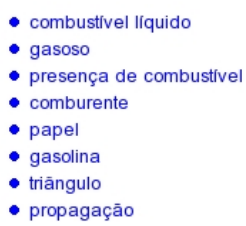

Fig. 4. Related concepts' area 
We included the Related Concepts area to encourage students to be continually mindful of the context they are exploring, taking into account the importance of context for effective learning

\section{Evaluating the Assisting - The Users' Opinions}

To evaluate whether the developed prototype is useful to support distance training, we conducted a survey in which 24 volunteers users participated. The most part of the participants were master candidates, contacted through email, who were not previously familiar with the specific workplace safety theme in our test.

The prototype was presented to the users, and then they were instructed to interact with the system, searching for desired topics related to the workplace safety theme. After that, the users' opinions were collected using an on-line questionnaire, which can be found at http://lia.dc.ufscar.br:8080/taticas/enquete_inicio.jsp (in Portuguese).

The questionnaire was divided into two parts. The first one was about the user's profile, where 3 questions about age, educational level and gender were asked. Then, five more questions about the users' satisfaction were asked.

The questions were designed in a 5 point Likert scale, including the responses, "Very useful, useful, does not matter, somewhat useful and not useful" and the users selected the option that was closest to their opinion. We also provided a free text field in case the user wanted to express additional comments.

Before filling out the questionnaire, the users received some information about the main objective of the research and ethical aspects, including confidentiality and privacy.

The users' profile identified by the three first questions shows that $83 \%$ of the users are males between 18 and 29 years old. About $42 \%$ are master candidate, $38 \%$ are undergraduate students, and $20 \%$ are high school students.

Around $79 \%$ of the users mentioned that it was easy or very easy to use, as shown in Table 1. Some comments made in the free text field were that "the system is simple to use and intuitive", and "it seems easy to interact and find things". It is important to point out that, although very few users classified the system as difficult to use, there were also comments such as "the system should show a message to the user when the concept was not found" and "...the way that data are presented could be more concise...", which point to the necessity of improvements to the interface.

Table 1. User's opinions about the analogy utility to understand the showed concept

\begin{tabular}{ll}
\hline User opinion & Percentage \\
\hline Very easy & $25.0 \%$ \\
Easy & $54.2 \%$ \\
Irrelevant & $12.5 \%$ \\
Difficult & $8.3 \%$ \\
Very difficult & $0 \%$ \\
\hline
\end{tabular}

Additionally, the survey showed that about $88 \%$ of them considered the system useful or very useful. We conclude that the system should be well accepted for its intended purpose, since there were no users that considered it of little or no help, as shown in Table 2. 
Table 2. User's opinions about the prototype utility

\begin{tabular}{ll}
\hline User opinion & Percentage \\
\hline Very useful & $20.8 \%$ \\
Useful & $66.7 \%$ \\
Irrelevant & $12.5 \%$ \\
Little useful & $0 \%$ \\
Not useful & $0 \%$ \\
\hline
\end{tabular}

The users were also asked about the analogies that were presented in the prototype. The first question asked about this issue was whether the user took note of the presence of analogies shown by the system. A high percentage of the users, about $88 \%$, commented that they noticed and appreciated them.

The second question asked if the user considered the use of analogy useful to understand the concept presented. Table 3 shows that $67 \%$ of the users considered that the analogies were useful or very useful, and taking into account only the users who noticed the presence of the analogies this percentage rise to $70 \%$. They also presented some comments like "I liked the analogies most because they help me to understand the subject that is being explained" and "the analogies were useful because gave clearer examples about the concepts' definition”. Those comments just confirm what many authors have already enunciated about the use of analogies in the learning process and demonstrate the relevance of the approach adopted in this study.

Table 3. User's opinions about the analogy's utility to explain the relevant concept

\begin{tabular}{ll}
\hline User opinion & Percentage \\
\hline Very useful & $20.8 \%$ \\
Useful & $66.7 \%$ \\
Little useful & $12.5 \%$ \\
Not useful & $0 \%$ \\
Analogies were not presented to me & $0 \%$ \\
\hline
\end{tabular}

Overall, the collected data in this survey demonstrates that most users considered the analogies useful in the learning process. Also, some observations were collected, in an optional field of the questionnaire. Following some examples are presented:

- “... the system is very interesting, especially for using analogies that facilitate the concepts' understanding from previous knowledge..."

- "... one suggestion is to drop the redundancy in some definitions..."

- "The analogies were satisfactory and coherent to the context."

- "... I had to spend some time analyzing the data before finding answers to specific questions!"

Some users criticized the fact that inclusion of the analogies sometimes causes redundancy, increasing the amount of text on the screen, possibly obscuring particular results that a user might wish to find. Comments like these should be analyzed to refine the system requirements, when systems like this are deployed for use in a real situation. 


\section{Conclusion and Future Works}

This work presents an on-line assistant for a distance training application, using a commonsense knowledge base to make analogies between topics in the curriculum material, and everyday life. Analogies play a very important role in the learning process, because they can be used in order to help people associate new things with known things through their similarities.

Large scale common sense knowledge bases can be used to build analogies that make sense for most people, because they take into account cultural knowledge shared by most people of a specific culture [1,2]. Explanation based on analogy has been known to help people understand new concepts $[1,2,11,16]$.

In order to verify the utility of the common sense-based approach adopted in the prototype, we conducted a survey. Respondents reported that the analogies were helpful in understanding the presented material.

Taking into account previous research [7, 16, 18, 19], we envision future work integrating the common sense engine into an instructional material editing tool, Cognitor [23], an authoring tool whose main objective is to support the teacher during the design and editing of instructional material to be delivered electronically.

The common sense engine could suggest analogies to teachers who were composing instructional material using Cognitor, so that they could be encouraged to present a suitable vocabulary, using analogies, and to present the new knowledge in a way that students can better understand.

According to Neris et al. [19], these characteristics improve the usability of the instructional material, which will be more deeply analyzed in future work.

\section{Acknowledgments}

We thank FAPESP (TIDIA-Ae FAPESP project, proc no. 05/60799-6, and Novas Fronteiras Program, proc no. 06/52412-7) and CAPES for financial support. We also thank the volunteers who have participated in the survey and all the volunteers who have been contributing their knowledge to build the Brazilian Open Mind Common Sense Knowledge base.

\section{References}

1. Anacleto, J.C., Lieberman, H., Tsutsumi, M., de Neris, V.P.A., de Carvalho, A.F.P., Espinosa, J., de Godoi, M.S., Zem-Mascarenhas, S.H.: Can Common Sense uncover cultural differences in computer applications? In: Proc. IFIP WCC2006, pp. 1-10. Springer, Heidelberg (2006)

2. Anacleto, J.C., Lieberman, H., de Carvalho, A.F.P., de Neris, V.P.A., de Godoi, M.S., Zem-Mascarenhas, S.H., Espinosa, J.: Using Common Sense to Recognize Cultural Differences. In: Sichman, J.S., Coelho, H., Rezende, S.O. (eds.) IBERAMIA 2006 and SBIA 2006. LNCS (LNAI), vol. 4140, Springer, Heidelberg (2006)

3. Anacleto, J.C., de Carvalho, A.F.P., de Neris, V.P.A., de Godoi, M.S., Zem-Mascarenhas, S.H., Talarico Neto, A., Lieberman, H.: How Can Common Sense Support Instructors with Distance Education? In: Brazilian Simposium on Informatics in Education (SBIE 2006), Brasília (2006) 
4. Anacleto, J.C., de Carvalho, A.F.P., de Neris, V.P.A., de Godoi, M.S., Zem-Mascarenhas, S.H., Talarico Neto, A., Lieberman, H.: Applying Common Sense to Distance Learning: the Case of Home Care Education. In: Brazilian Symposium on Human-Computer Interaction - IHC 2006, Natal (2006)

5. Ausubel, D.P.: Significado y aprendizaje significativo. In: Psicología educativa: un punto de vista cognoscitivo, Editorial Trillas,Mexico, pp. 55-107 (1976) (in Spanish)

6. Brazilian Open Mind Common Sense Website (Visited in January 2006), http://www.sensocomum.ufscar.br

7. Beckman, P.: Strategy instruction: ERIC clearinghouse on disabilities and gifted education arlington. Disponível em: (2002)(Visited on January 2007), http://ericec.org/digests/ e638.html

8. Cambridge Dictionaries Online (Visited on January 2007), Available in http://dictionary.cambridge.org/

9. de Carvalho, A.F.P.: Investigando o Uso de Senso Comum para Apoiar as Práticas de eLearning. In: Qualificação (Mestrado em Ciência da Computação), p. 106. Universidade Federal de São Carlos, São Carlos (2006) (in Portuguese)

10. Doube, W.: Distance Teaching Workloads. In: Technical Symposium on Computer Science Education. ACM SIGCSE Proceedings, Austin, pp. 347-351. ACM Press, New York (2000)

11. Espinosa, J.H.: Reducing Complexity of Consumer Electronics Interfaces Using Commonsense Reasoning, Master Thesis. MIT Media Laboratory (2005)

12. Freire, P.: Pedagogia da autonomia: saberes necessários à prática educativa, 31 th edn., São Paulo, Paz e Terra (1996) (in Portuguese)

13. Freinet, C.: Education through work: A model for child centered learning. Edwin Mellen Press, New York (1993)

14. Gagné, R.: The Conditions of Learning, 3rd edn., Holt, Rinehart \& Winston (1974)

15. Lieberman, H., Kumar, A.: Providing expert advice by analogy for on-line help. In: Proc. IEEE/WIC/ACM International Conference On Intelligent Agent Technology, France (Compiègne), pp. 26-32. IEEE Computer Society, US (Washington, DC) (2005)

16. Liebman, J.: Teaching Operations Research: Lessons from Cognitive Psychology. Interfaces 28(2), 104-110 (1998)

17. Matocha, J., Camp, T., Hooper, R.: Extended analogy: an alternative lecture method. In: Proceedings of the twenty-ninth SIGCSE technical symposium on Computer science education, Atlanta, Georgia, United States, pp. 262-266.

18. de Neris, V.P.A., Anacleto, J.C.: Planejamento Estratégico para Educação Apoiada por Computador Visando a Produção de Material Instrucional para EAD Baseado em Estratégias Cognitivas(Strategic Planning for CSCL aiming at DL instructional material prodution based on Cognitive Strategies). In: XXIV Computer Brazilian Society Congress WIE Workshop on Informatics at School, 2004, Salvador. XXIV Computer Brazilian Society Congress Proceedings, vol. 1, pp. 1-11 (2004) (in Portugese)

19. de Neris, V.P.A., Talarico Neto, A., Anacleto, J.C., Zem-Mascarenhas, S.H.: Hyper Documents with Quality for Distance Learning: Cognitive Strategies to Help Teachers in the Navigational Project and Content Organization. In: Brazilian Symposium on Multimedia and Web Systems, 2005, 125th edn., Poços de Caldas, Brazil. ACM International Conference Proceeding Series, vol. 125, pp. 1-7 (2005)

20. Rosenshine, B.: The Case for Explicit, Teacher-led, Cognitive Strategy Instruction. In: Annual Meeting of the American Educational Research Association. Chicago (1997) 
21. Singh, P.: The public acquisition of commonsense knowledge. In: Proc of AAAI Spring Symposium on Acquiring (and using) Linguistic (and world) Knowledge for Information Access, US (Palo Alto, CA) (2002)

22. Stamm, S.: Mixed nuts: atypical classroom techniques for computer science courses. Crossroads 10(4). ACM Press

23. Talarico Neto, A., Anacleto, J.C., de Neris, V.P.A., de Godoi, M.S.G., de Carvalho, A.F.P.: Cognitor: Um framework baseado na linguagem de Padrões Cog-Learn. In: Brazilian Simposium on Informatics in Education (SBIE 2006), Brasília (2006)

24. West, C.K., Farmer, J.A., Wolff, P.M.: Instructional Design: Implications from Cognitive Science. Massachusetts (Boston): Allyn and Bacon (1991)

25. Zhang, D., Zhao, J.L., Zhou, L., Nunamaker, J.F.: Can e-learning replace classroom learning? In: Communications of the ACM, may, vol. 47(5), pp. 75-79. ACM Press, US (New York, NY) (2004)

26. Anderson, R.E.: Social impacts of computing: Codes of professional ethics. Social Science Computing Review 2, 453-469 (1992)

27. ACM SIG Proceedings template: www.acm.org/sigs/pubs/proceed/template.html

28. Conger, S., Loch, K.D. (eds.): Ethics and computer use. Com., vol. 38(12). ACM Press, New York

29. Mackay, W.E.: Ethics, lies and videotape. In: Proceedings of CHI '95, Denver CO, pp. 138-145. ACM Press, New York (1995)

30. Schwartz, M.: Task Force on Bias-Free Language: Guidelines for Bias-Free Writing. Indiana University Press, Bloomington, IN (1995) 